\title{
GRATIC: Uma metodologia para gestão de riscos em aquisições de TIC
}

\author{
Fabiana Ferreira Cardosoํ, Carina Frota Alves² \\ ${ }^{1}$ Coordenação de Governança de TIC - Instituto Federal de Educação do Tocantins \\ Palmas - TO - Brasil \\ ${ }^{2}$ Centro de Informática - Universidade Federal de Pernambuco (UFPE) \\ Recife - PE - Brasil \\ fabiana.cardoso@ifto.edu.br, cfa@cin.ufpe.br
}

\begin{abstract}
This article presents the steps for the construction of a systematized methodology for risk management in ICT acquisitions within Brazilian public institutions. The Design Science Research method was used because it is an approach that seeks to solve a problem from the understanding of a real situation. To understand the problem, two questionnaires were conducted with participants from Federal Institutes of Education. The GRATIC methodology was proposed as novel contribution. A case study was conducted to demonstrate and evaluate the feasibility of the proposal. The results suggest that to achieve continuous process improvement, maximization of transparency of administrative acts and collaborative learning, one can use the sharing of lessons learned through a risk inventory, risk management map and a digital repository of information.
\end{abstract}

Resumo. Este artigo apresenta as etapas para a construção de uma metodologia sistematizada para gestão de riscos em aquisições de TIC no âmbito das instituições públicas brasileiras. O método Design Science Research foi utilizado por ser uma abordagem que busca solucionar um problema a partir do entendimento de uma situação real. Para entender o problema, foram realizados dois questionários com servidores de Institutos Federais de Educação a fim de entender a situação atual. A metodologia GRATIC foi proposta como nova contribuição. Um estudo de caso foi realizado para demonstrar e avaliar a viabilidade da proposta. Os resultados obtidos sugerem que para obter a melhoria contínua do processo, a maximização da transparência dos atos administrativos e o aprendizado colaborativo, pode-se utilizar o compartilhamento de lições aprendidas através de um inventário de riscos, mapa de gerenciamento de riscos e um repositório digital de informações.

\section{Introdução}

De acordo com Pires (2016) e Parreira (2018), de maneira geral as aquisições que envolvem Tecnologia da Informação e Comunicação (TIC) na Administração Pública Federal (APF) costumam ser bastante complexas e burocráticas, exigindo conhecimento técnico aprofundado, além de competências para planejar e gerir adequadamente a contratação, conforme determina a legislação vigente. Apesar do aporte legal que subsidia o processo de aquisição, é comum haver divergências entre o que foi planejado e a efetiva execução do contrato, na maioria das vezes ocasionadas pela diferença entre preço licitado e o valor praticado pelo mercado. 
Pires (2016), Nobre (2017) e Souza (2017) afirmam que as dificuldades relacionadas ao processo de aquisição de TIC geram incertezas envolvendo recursos financeiros, humanos, materiais e tecnológicos, o que traz diversos riscos e insegurança para os gestores. Sabe-se que as incertezas, na maioria das vezes, ocasionam interrupção do processo licitatório, atrasos na entrega de bens e serviços e até mesmo fracasso no processo de aquisição, consequentemente impactam a qualidade da prestação de serviços governamentais.

Para Brasil (2018) embora grande parte das instituições públicas brasileiras sigam um modelo de gestão de riscos definido pelo governo federal, o controle de riscos não é realizado de forma eficiente em todas as fases do processo de aquisição de TIC. Para este órgão de controle a falta de procedimentos sistemáticos faz com que os riscos não sejam efetivamente gerenciados podendo acarretar insucesso no alcance das metas e objetivos organizacionais.

Neste sentido, os órgãos de controle como o Tribunal de Contas da União (TCU) têm reportado nos últimos anos suas preocupações. No levantamento realizado por Brasil (2018b) em 2017, é possível observar que $86 \%$ das organizações que preencheram o questionário de autoavaliação sobre governança pública brasileira, declararam que não estabeleciam diretrizes para gerir riscos nas aquisições e $88 \%$ não realizavam nenhuma prática sistemática de gestão de riscos. No relatório de acompanhamento divulgado em 2018 este órgão de controle mostrou que das 498 organizações públicas federais que preencheram o levantamento de governança pública, $82 \%$ das organizações não adotam práticas de gestão de riscos de TI e $71 \%$ das organizações estão no estágio inicial de maturidade em gestão de riscos em contratações públicas.

$\mathrm{Na}$ busca de compreender o problema apresentado, esta pesquisa investiga "Como sistematizar a gestão de riscos em aquisições de TIC através de uma metodologia no âmbito das instituições públicas brasileiras?" Baseado neste questionamento, o objetivo central deste artigo é propor uma metodologia sistemática para gerenciar riscos em aquisições de TIC no contexto das instituições públicas brasileiras.

A justificativa para este estudo é que embora existam metodologias de gestão de riscos que possam ser utilizadas no contexto das aquisições de TIC, apresentadas por Silva (2014), Silva (2016), Souza (2017), Nobre (2017), CGU (2018) e Bermejo (2019), não foi possível identificar uma abordagem prática, padronizada, sistemática e transparente envolvendo o aprendizado e compartilhamento de conhecimento sobre gestão de riscos em todas as fases de aquisição de TIC (planejamento da contratação, seleção do fornecedor e gestão do contrato). Grande parte de propostas apresentadas na literatura científica envolvem apenas o processo de planejamento da contratação.

Sendo assim, este estudo será detalhado nas seguintes seções: Seção 2 apresenta alguns conceitos apresentados por autores e organizações; a Seção 3 descreve a metodologia de pesquisa; Seção 4 descreve como foi realizada a investigação do problema; Seção 5 traz a proposta para solução do problema; Seção 6 mostra como foi realizada a demonstração e avaliação da metodologia GRATIC; e finalmente a Seção 7 descreve conclusões, limitações e trabalhos futuros.

\section{Gestão de Riscos}

Segundo HM Governmenth (2019), as organizações do setor público não podem ser 
avessas ao risco e serem bem-sucedidas. O risco é inerente a tudo o que a organização faz para fornecer serviços de alta qualidade, por isso deve ser gerenciado. Para a norma ISO (2018) risco é o efeito da incerteza nos objetivos. É um desvio em relação ao esperado. Pode ser negativo, positivo ou ambos e pode abordar, criar ou resultar em oportunidades e ameaças.

De acordo com Hopkin (2018), a gestão de riscos quando implementada de forma adequada, traz vários benefícios, tais como: fornecimento de informações estruturadas adicionais para auxiliar a tomada de decisão, a melhoria da eficiência das operações, a garantia de que os processos de negócios sejam eficazes e que a estratégia forneça exatamente o que é necessário à entrega eficaz de projetos e programas de trabalho.

Neste sentido, Souza (2017) afirma que a gestão de riscos deve ser realizada de forma sistematizada considerando a análise do contexto de determinado processo ou atividade, identificar o pode dar errado no processo, avaliar o tamanho do potencial problema, definir a forma de tratamento para evitar que a situação aconteça e monitorar e ajustar os controles aplicados. Ao identificar, analisar, avaliar e desenvolver estratégias de contingenciamento de riscos, deve-se incentivar a proatividade e não na reatividade, tornando o controle de riscos estruturado e eficiente. Para Nobre (2017), o processo de gestão de riscos nas contratações de Tecnologia da Informação deve fornecer aos gestores um entendimento das ameaças que podem afetar o sucesso dos projetos de aquisição de TIC, permitindo aos gestores reduzir problemas e alcançar seus objetivos estratégicos.

\section{Metodologia de Pesquisa}

Esta pesquisa é de natureza aplicada, pois segundo Gil (2019) objetiva gerar conhecimentos para a aplicação prática, dirigida à solução de problemas específicos. $\mathrm{O}$ método de pesquisa escolhido para o desenvolvimento do estudo foi o Design Science Research (DSR), utilizando a metodologia proposta por Peffers et al. (2007), por ter uma sequência lógica de 6 etapas que devem ser seguidas, podendo ser repetidas de forma a melhorar a solução proposta. Para a obtenção de dados necessários para a construção da proposta foram realizadas: pesquisa documental, bibliográfica e estudo de caso. A abordagem do problema é qualitativa, no qual se busca entender um fenômeno específico em profundidade, trabalha com descrições, comparações e interpretações, ao invés de estatísticas, regras e outras generalizações (Marconi; Lakatos, 2017). O estudo de caso foi realizado como estratégia de pesquisa, porque aborda a questão "como", e as pesquisadoras tiveram pouco controle sobre os eventos e o foco foi direcionado para um fenômeno contemporâneo inserido no contexto da vida real das instituições públicas brasileiras, conforme recomenda Yin (2015). As entrevistas foram feitas de forma a validar a proposta da solução e o grupo focal foi definido para demonstrar e avaliar a metodologia GRATIC.

A primeira etapa (identificação do problema e a motivação) envolveu o entendimento do problema e justificativa da sua importância considerando sua relevância da solução para a sociedade. Dezoito institutos federais de educação participaram do levantamento de informações feito através da aplicação de dois questionários $^{1}$. Na segunda etapa (definição dos objetivos da solução) definiu-se os objetivos da solução, ou seja, diz respeito à definição dos resultados esperados para o problema que se busca resolver: gerenciar riscos de forma sistematizada no processo de

1 Questionários 
aquisição de TIC. A terceira etapa (projeto e desenvolvimento) foram desenvolvidos e implementados três artefatos: inventário de riscos, mapa de gerenciamento de riscos e repositório digital de informações. A quarta etapa (demonstração) consistiu no uso da solução de forma prática no contexto investigado, sendo efetuada por meio de estudo de caso em um instituto federal de educação na região norte do país. A quinta etapa (avaliação) de acordo com Peffers et al. (2007) explica o que deve ser analisado e testado de acordo com as condições estabelecidas para validação. Nesta etapa, observamos e medimos como os artefatos propostos se comportavam no sentido de solucionar o problema. Esta etapa foi realizada por meio de grupo focal com oito pessoas. A última etapa (sexta) consistiu em comunicar tanto o problema que foi estudado como, também sua importância e como ele pode ser solucionado. Nesta etapa foi apresentado o rigor com o qual a pesquisa foi conduzida, bem como o quão eficaz foi a solução encontrada para o problema.

Em resumo, para realização deste estudo foram adotadas as recomendações de Yin (2015), Marconi e Lakatos (2017), e Gil (2019). A coleta dos dados da etapa de demonstração e avaliação da proposta foi feita através de entrevistas e grupo focal ${ }^{2}$ com oito servidores públicos de um instituto federal de educação. O critério utilizado para escolha dos participantes foi o tempo de experiência no processo de aquisições de TIC. O cenário escolhido para a realização da pesquisa é o contexto das instituições públicas brasileiras, por isso foi escolhido um Instituto Federal de Educação que vem enfrentado dificuldades em gerir riscos em aquisições de TIC. Esta instituição foi escolhida por conveniência, pela maior facilidade de acesso às informações, proporcionando assim uma amostra válida, aumentando a confiabilidade dos dados obtidos.

A pesquisa foi realizada de junho a dezembro de 2019. Os questionários foram aplicados entre os meses de junho a julho de 2019. O estudo de caso e grupo focal foram realizados concomitantemente entre os meses de outubro a novembro de 2019.

\section{Investigação do Problema}

A investigação do problema foi realizada de forma a compreender as dificuldades enfrentadas pelas instituições públicas brasileiras e capturar as informações necessárias para construção da metodologia de gestão de riscos em aquisições de TIC (GRATIC). Como instrumento de coleta de dados foram utilizados dois questionários ${ }^{2}$. Para $\mathrm{o}$ design do artefato foram coletadas informações sobre como o processo deve ser realizado conforme a legislação vigente (processo), como as pessoas realizam as atividades na prática (pessoas), o que é preciso para estar em conformidade legal (legislação), o que a organização já tem para a gestão de riscos em aquisições de TIC (organização), como as informações são documentadas e comunicadas (comunicação) e quais tecnologias são necessárias (tecnologia).

O primeiro formulário aplicado no mês de junho de 2019 abordou como o processo de aquisição de TIC é executado na prática no contexto das instituições públicas brasileiras, ou seja, quais são as normativas utilizadas, qual o modelo adotado para realizar aquisições de TIC, quais são os problemas e dificuldades na execução do processo e as melhorias necessárias. O segundo formulário aplicado no mês de julho tratou sobre a gestão de riscos em aquisições de TIC, ou seja, como a instituição executa o processo de gestão de riscos, suas etapas/fases, problemas ocorridos durante a execução do gerenciamento de riscos, quais são as variáveis influenciadoras, as técnicas utilizadas para identificação, análise, avaliação e tratamento e relato de riscos, como é

2 Entrevistas e Grupo Focal 
feito o monitoramento e controle, a conscientização e o entendimento do risco, a comunicação sobre riscos, o registro das lições aprendidas no decorrer do processo, soluções e ferramentas tecnológicas utilizadas.

Os participantes dos questionários ${ }^{2} 1$ e 2 relatam que a maioria das informações sobre a gestão de riscos em aquisições de TIC não estão visíveis para todos, como por exemplo a realização do monitoramento, controle, registro e relato de riscos no decorrer da execução das fases do processo de aquisição. A partir das informações coletadas foi possível observar que a gestão de riscos em aquisições de TIC no contexto dos Institutos Federais de Educação é realizada de forma diferente em cada instituição. Com isso, é possível afirmar que nem sempre as instituições públicas conseguem seguir as recomendações da legislação vigente.

A partir das respostas obtidas nos questionários 1 e 2 sobre gestão de riscos em aquisições de TIC foram identificadas várias causas para a dificuldade em gerir riscos neste processo. Para facilitar a compreensão o diagrama de espinha de peixe apresentado na Figura 1 mostra as causas categorizadas nas perspectivas pessoas, processos, organização, comunicação, legislação e tecnologia).

\section{AQUISICG̃ES DETIC PROBLEMA}

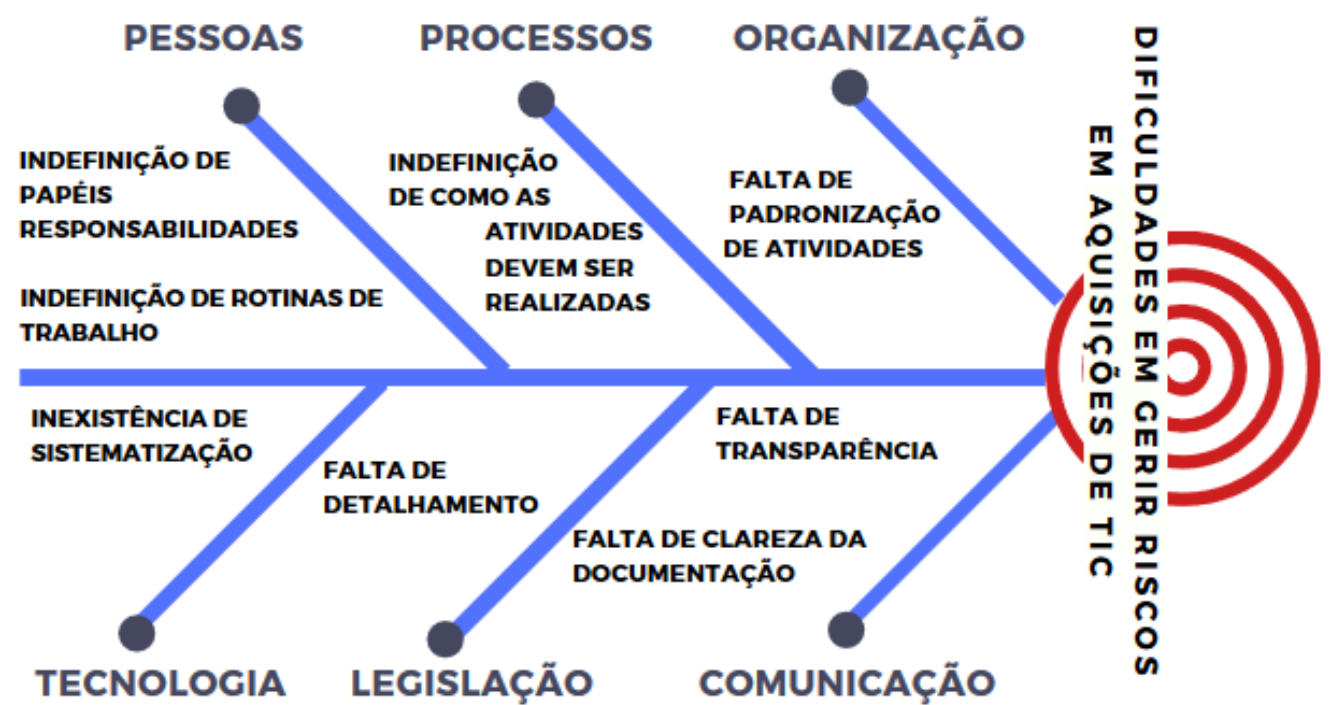

Figura 1. Causas-raiz para dificuldades em gerir riscos em aquisições de TIC

Conforme demonstra a Figura 1 a perspectiva pessoas apresenta a indefinição de papéis e responsabilidades e a indefinição de rotinas de trabalho. Processos verifica-se a indefinição de como as atividades devem ser realizadas. Organização constata-se a falta de padronização de atividades. A comunicação por sua vez está relacionada com a falta de transparência dos procedimentos adotados pela equipe de contratações de TIC e a falta de clareza dos documentos gerados no processo aquisitivo, como por exemplo o termo de referência e o edital.

Segundo os participantes que responderam os questionários 1 e 2, nem sempre há o detalhamento da legislação sobre a gestão de riscos em aquisições de TIC, o que 
dificulta a execução do processo. Embora tem-se tecnologias desenvolvidas para realização de gestão de riscos de forma abrangente que podem ser utilizadas para a gestão de riscos de um setor, processo, atividade, nem sempre há a sistematização das rotinas, atividades e tarefas envolvendo o aprendizado colaborativo. A Figura 2 apresenta as barreiras e facilitadores que devem ser considerados para tornar o processo de gestão de riscos em aquisições de TIC sistematizado, segundo a opinião dos participantes deste estudo.

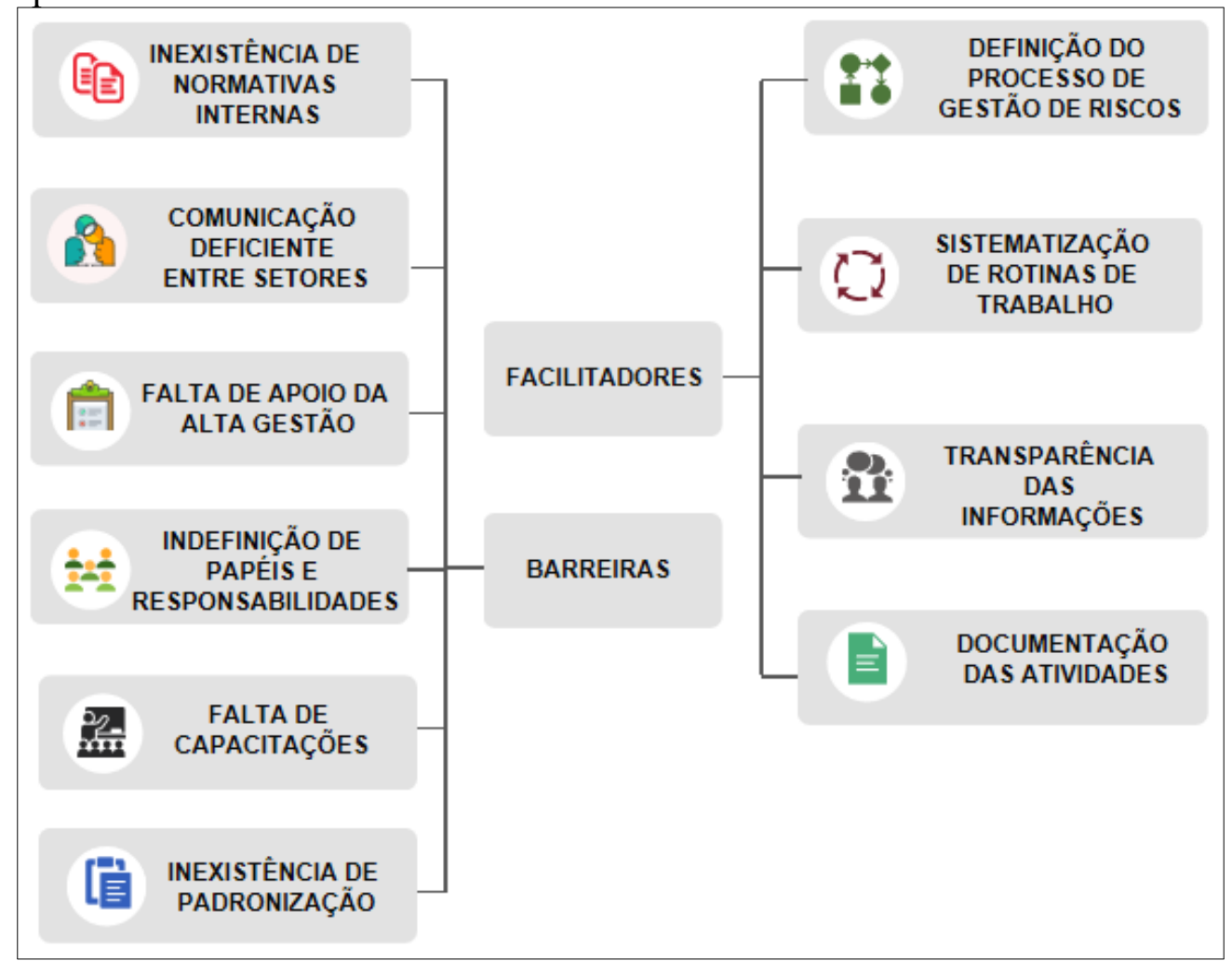

Figura 2. Barreiras e facilitadores para a gestão de riscos em aquisições de TIC

De acordo com a opinião dos participantes que responderam os questionários, para realizar a gestão de riscos em aquisições de TIC dentro das instituições públicas brasileiras existem seis barreiras e quatro facilitadores. Dentre as barreiras a não padronização para atividades, tarefas e artefatos é o fator que mais compromete a eficiência do processo. Como fator imprescindível para o sucesso da gestão de riscos em aquisições de TIC tem-se a definição clara e objetiva dos papéis e responsabilidades de cada ator envolvido na execução do processo.

\section{Design da solução - metodologia GRATIC}

A metodologia de Gestão de Riscos em Aquisições de TIC - GRATIC ${ }^{3}$ foi desenvolvida com base nas perspectivas: pessoas, processos, organização, comunicação, legislação e tecnologia definidas no decorrer da investigação do problema. Para a elaboração da proposta foi levado em consideração o contexto interno e externo das instituições públicas brasileiras, bem como a opinião de especialistas na área de aquisições de TIC.

O processo de gestão dos riscos adotado pela metodologia GRATIC é baseado nas recomendações publicadas por Brasil (2019) através da Instrução Normativa SGD/ ME No 1, de 4 de abril de 2019, Brasil (2017) por meio da Instrução Normativa MPOG

3 Metodologia GRATIC 
$N^{0}$ 5, de 26 de maio de 2017 e Brasil (2016) na Instrução Normativa Conjunta MP/CGU $\mathrm{N}^{\mathrm{o}}$ 1, de 10 de maio de 2016. Esta proposta utiliza técnicas, ferramentas, procedimentos e artefatos para a identificar, avaliar, tratar, monitorar, controlar, documentar e comunicar riscos em aquisições de TIC. As fases estão estruturadas em um ciclo iterativo e incremental inspiradas no ciclo de melhoria contínua PDCA (planejar, desenvolver, checar e agir), conforme apresenta a Figura 3.

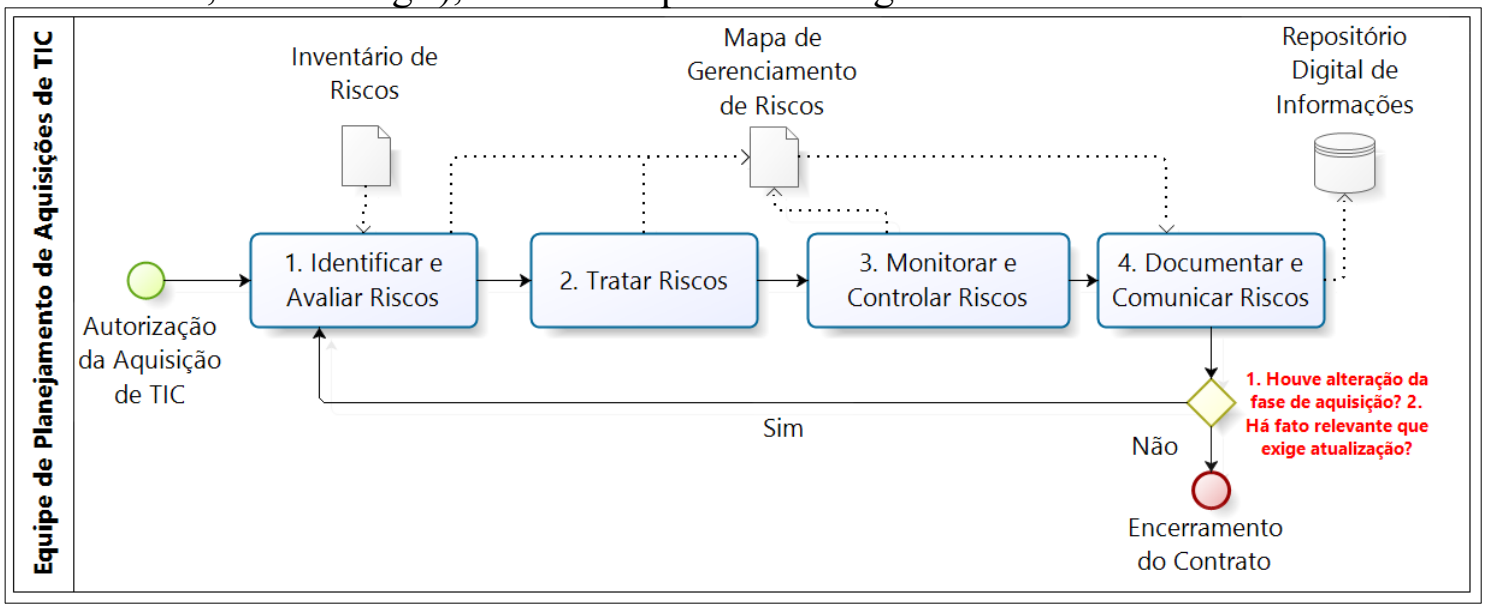

Figura 3. GRATIC: metodologia de gestão de riscos em aquisições de TIC

A Figura 3 mostra o fluxo do processo de gestão de riscos em aquisições de TIC proposto pela metodologia GRATIC. A proposta apresenta três artefatos para auxiliar o processo de gestão de riscos em aquisições de TIC, o inventário de riscos sobre contratações de TIC, mapa de gerenciamento de riscos e o repositório digital de informações. Este processo é composto por quatro fases:

- Fase 1 (identificar e avaliar riscos) consiste em identificar, analisar e avaliar riscos e ameaças que possam vir a comprometer o sucesso da aquisição de TIC. Esta fase contém procedimentos para registrar, analisar e avaliar riscos, classificando-os em níveis de criticidade de acordo com a probabilidade e impacto de ocorrência dos mesmos.

- Fase 2 (tratar riscos) é responsável por definir a resposta ao risco, comparando os resultados encontrados com os critérios para tratamento de riscos previamente definidos e determina se o risco identificado exige tratamento. Esta fase contempla procedimentos para a elaboração de respostas aos riscos com o objetivo de reduzir as ameaças levantadas.

- Fase 3 (monitorar e controlar riscos) monitora o comportamento dos riscos ao longo do tempo de execução do processo de aquisição de TIC. Esta fase contém procedimentos para verificar se os riscos ainda existem e executar o controle quanto à adequação do perfil de tolerância aos riscos definidos pela instituição.

- Fase 4 (documentar e comunicar riscos) registra e relata riscos que ocorrem durante o processo de aquisição de TIC. Esta fase é responsável por executar procedimentos para documentar e informar riscos e as ações de prevenção ou mitigação de acordo com o plano de tratamento de riscos.

As quatro fases do processo de gestão de riscos em aquisições de TIC proposto pela metodologia GRATIC são compostas por procedimentos baseados em técnicas 
recomendadas para gestão de riscos: brainstorming, entrevista estruturada e semiestruturada, lista de verificação, questionário e opinião especializada. Além disso, são utilizadas as ferramentas: $5 \mathrm{~W} 2 \mathrm{H}$, gráficos, planilhas, relatórios, mapa de risco e planos. $\mathrm{O}$ artefato mapa de gerenciamento de riscos ${ }^{4}$ contempla todas as ferramentas $\mathrm{e}$ técnicas utilizadas pela metodologia GRATIC.

\section{Demonstração e Avaliação}

O estudo de caso realizado nesta pesquisa teve como objetivo demonstrar e avaliar o uso da metodologia GRATIC em um contexto real. Para isso, selecionamos um Instituto Federal de Educação que vem enfrentando ao longo dos anos dificuldades no gerenciamento de riscos em aquisições de TIC. Os participantes da avaliação desta proposta foram oito servidores públicos lotados nesta instituição, especialistas na área de aquisições de TIC, que atuam ativamente na equipe de planejamento da contratação.

Para demonstrar e avaliar a metodologia GRATIC foi definido o roteiro para o estudo de caso observando as recomendações de Yin (2015), são elas: definição do contexto da instituição, público-alvo, apresentação, uso, avaliação e resultados obtidos com o uso da solução, contribuições dos especialistas na área e avaliação crítica da solução. Como estratégia para avaliação da solução foi definido o uso de grupo focal para simular dois processos de aquisição que são comuns a todas as instituições públicas brasileiras. A demonstração e avaliação da proposta foi realizada durante um mês possibilitando a validação da eficácia e viabilidade prática de seu uso no contexto das instituições públicas brasileiras, bem como também realizar o mapeamento dos riscos que são comuns em todos os processos de aquisição na área de TIC. Estes riscos foram mapeados no inventário de riscos. A Figura 4 apresenta alguns destes riscos, categorizados nas 3 fases da contratação: planejamento, seleção do fornecedor e gestão do contrato.

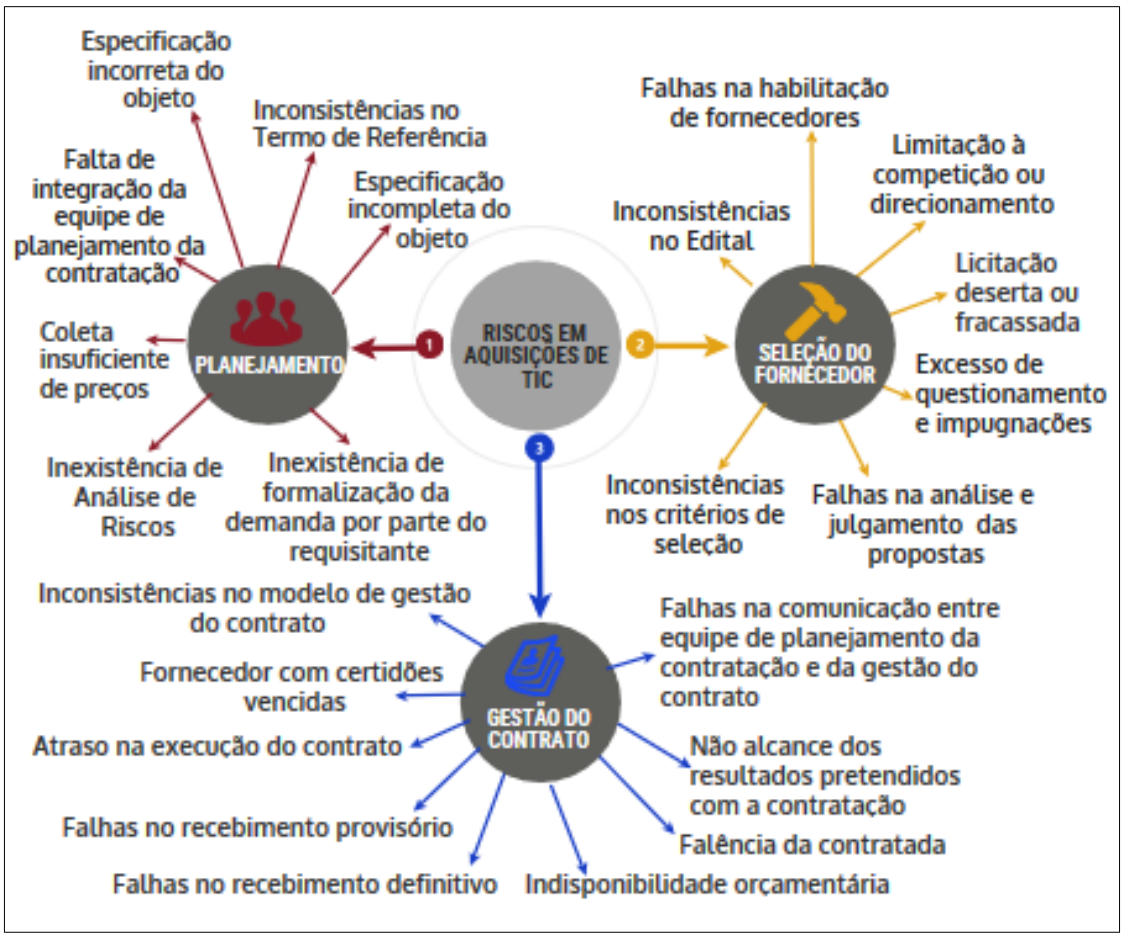

Figura 4. Riscos comuns em aquisições de TIC

4Mapa de Gerenciamento de Riscos 
Os resultados obtidos sugerem uma redução na incidência de riscos a medida que os mesmos são mapeados e mitigados. Em processos realizados em anos anteriores, segundo a opinião dos participantes do estudo, ocorriam muitos questionamentos e impugnações por falta de comunicação entre a equipe de planejamento da contratação e a equipe de apoio. Isso tende a não ocorrer mais, uma vez que o risco foi identificado, analisado, avaliado, tratado e documentado. Com o uso frequente da metodologia GRATIC, espera-se que a ocorrência de riscos tende a baixar em razão o aprendizado colaborativo e a transparência do processo.

Observa-se ao longo da execução das fases da metodologia GRATIC, que os controles de mitigação de riscos são aperfeiçoados de forma que os riscos são administrados, não ocasionando impactos negativos significativos para a instituição. A Tabela 1 apresenta os resultados obtidos na avaliação da proposta deste estudo, feitas por meio de simulações com o grupo focal.

Tabela 1. Comparativo de riscos ocorridos em processos diferentes de aquisição

\begin{tabular}{|c|c|c|}
\hline \multirow{2}{*}{$\begin{array}{c}\text { Riscos ocorridos nos dois } \\
\text { momentos de uso da MGR- } \\
\text { GRATIC }\end{array}$} & \multicolumn{2}{|c|}{ Aquisição de TIC } \\
\hline & Equipamentos de TIC & Prestação de Serviço \\
\hline Questionamentos & 4 & 3 \\
\hline Impugnações & 3 & 2 \\
\hline Riscos identificados & 63 & 87 \\
\hline Riscos ocorridos & 9 & 7 \\
\hline Riscos mitigados & 9 & 7 \\
\hline $\begin{array}{llll}\begin{array}{l}\text { Correção de } \\
\text { Referência }\end{array} & & \text { Termo de } \\
\text { Refor } & & \\
\end{array}$ & 4 & 2 \\
\hline Correção de Edital & 4 & 3 \\
\hline
\end{tabular}

Os resultados apresentados na Tabela 1 indicam que a proposta apresenta informações necessárias para auxiliar a gestão de riscos envolvendo aquisições de TIC no âmbito dos Institutos Federais de Educação. A avaliação crítica por parte da equipe de planejamento da contratação e apoio, participantes do estudo de caso, mostrou-se viável no contexto de uma instituição federal de educação, uma vez que se verifica o controle maior do processo e a diminuição de riscos segundo a opinião dos participantes do grupo focal.

Os resultados iniciais sugerem que a solução proposta pode ser usada em outras instituições públicas brasileiras. Entretanto, mesmo com o resultado positivo, é necessário realizar avaliações em outras entidades que compõem a Administração Pública, uma vez que cada organização possui suas peculiaridades e realiza a gestão de riscos de forma diferente, de acordo com sua realidade e capacidade técnica da equipe de planejamento da contratação. Vale ressaltar que a eficiência da gestão de riscos em aquisições de TIC exige um esforço inicial para validar todos os riscos na primeira fase (identificar e avaliar riscos). Isso ocorre em razão de que o conhecimento sobre a gestão de riscos depende da experiência dos envolvidos e da necessidade de cada organização, bem como de constantes mudanças no contexto interno e externo da instituição. Sabe-se que para cada processo aquisitivo existem riscos e controles diferentes a serem observados.

Sendo assim, o diferencial desta solução em relação às demais metodologias existentes no mercado, deve-se ao fato de dispor de um inventário contendo riscos e controles divulgado por Brasil (2014) e outras instituições públicas, o que permite que a equipe de planejamento da aquisição possa adaptá-lo à sua realidade e necessidade, uma vez que as fases estão previamente definidas e validadas por especialistas em aquisições 
de TIC. Além disso, utiliza uma planilha documentadora denominada mapa de gerenciamento de riscos e um repositório digital de informações que devem ser utilizados para o compartilhamento do aprendizado e transparência dos atos administrativos no decorrer do processo aquisitivo.

\section{Conclusões, Limitações e Trabalhos Futuros}

Ao realizar a gestão de riscos em aquisições de TIC dentro do contexto das instituições públicas brasileiras observa-se que o processo tem se tornado mais oneroso e complexo em razão das atualizações na legislação brasileira. Uma vez que os riscos não são gerenciados, podem impactar no não cumprimento dos objetivos organizacionais. $\mathrm{O}$ objetivo desta pesquisa foi propor uma metodologia sistematizada de gestão de riscos em aquisições de TIC. Para isso, foi realizada a investigação do problema com a aplicação de dois questionários e foi conduzido um estudo de caso por meio de entrevistas e grupo focal com especialistas na área de aquisições de TIC para demonstrar e avaliar a proposta de solução para o problema.

Os resultados obtidos indicam que a solução se mostra viável do ponto de vista prático. A metodologia GRATIC obteve uma boa aceitação por parte dos membros da equipe de planejamento da contratação, ou seja, dos oito participantes, cinco consideraram que a solução é capaz de executar as atividades necessárias para realizar a gestão de riscos em aquisições de TIC. Apenas um participante considera não viável e dois acham que a metodologia tem que ser utilizada continuamente para se tornar eficiente. Em geral, os participantes do estudo de caso concordam que a solução apresentada seja viável do ponto de vista da equipe de planejamento da contratação e apoio. Entretanto, um participante afirma que a metodologia GRATIC deveria apresentar um software específico para monitoramento e controle contínuo das fases e não uma planilha documentadora.

Optou-se por manter a planilha documentadora em razão da facilidade de uso, não dependência de tecnologia e pessoas especializadas na correção e atualização de fórmulas para cálculo de probabilidade e impacto e alterações de gráficos de indicadores. Além disso, nem todas as instituições públicas brasileiras dispõem de recursos tecnológicos para implantação e atualização de software, uma vez que o país vem passando por vários cortes orçamentários, o que poderia inviabilizar o uso da metodologia GRATIC por meio da necessidade de instalação de um software.

Outra característica observada é que a metodologia GRATIC aborda o controle de atividades de gestão de riscos de forma acessível a todos, bastando apenas ter acesso a um único arquivo eletrônico, podendo ser utilizado em diversas plataformas tecnológicas em qualquer lugar, online ou offline. Neste sentido, pode ser um instrumento para apoiar a tomada de decisão em relação a ações de monitoramento e controle de riscos no processo de aquisições de TIC e possibilita o aprendizado colaborativo e a transparência do processo.

A partir das informações obtidas através do grupo focal realizado com os participantes do estudo de caso verificou-se a necessidade de aplicar a metodologia GRATIC em outros contextos reais, de forma contínua, a fim de registrar as lições aprendidas podendo agilizar o gerenciamento de riscos em aquisições de TIC nas instituições públicas brasileiras. Sendo assim, o estudo apresenta limitações em relação ao público-alvo escolhido e escopo de atuação.

O público-alvo para realização do estudo de caso é composto por membros da 
equipe de planejamento da contratação de TIC, formado por 8 pessoas de apenas um Instituto Federal de Educação. Portanto, devem ser observadas e consideradas as seguintes limitações: as informações obtidas através dos questionários, entrevistas e grupo focal estão limitadas a opiniões pessoais dos participantes desta pesquisa, restritas a experiências práticas obtidas por meio de participação em diversos processos de aquisição de TIC; é importante a realização de avaliações da metodologia GRATIC em outras instituições de ensino, pois cada equipe de planejamento da contratação tem suas características, habilidades e competências que influenciam o resultado final do processo; o estudo de caso considerou apenas o ponto de vista dos especialistas que atuam diretamente com aquisições de TIC e que participam da equipe de planejamento da contratação, podendo não representar a opinião dos demais atores envolvidos no processo de aquisição como fornecedores, integrante requisitante, fiscal administrativo do contrato; o grupo focal utilizou para a avaliação da proposta apenas processos de aquisição relativamente simples e com pouca complexidade de serem conduzidos pela equipe de planejamento da contratação.

Ressalta-se que este estudo propôs uma abordagem prática e sistematizada para gestão de riscos apresentando fases, técnicas, ferramentas, procedimentos e artefatos aplicados ao processo de aquisição de TIC no contexto das instituições públicas brasileiras. Os especialistas da área de aquisições de TIC que participaram do estudo de caso concordaram com a viabilidade prática tendo em vista que a solução proposta é embasada em normativas sobre gestão de riscos utilizadas pela administração pública federal, podendo ser adaptada para uso não somente no contexto educacional mas também em outros contextos públicos, uma vez que as fases definidas foram escritas em conformidade com a legislação vigente e abordagens sobre gestão de riscos adotadas pelo mercado.

Vale ressaltar que uma importante contribuição deste estudo é a integração de riscos e controles já estabelecidos pelos órgãos públicos através do inventário de riscos detalhado na planilha documentadora (mapa de gerenciamento de riscos), que foi disponibilizada no repositório digital de informações ${ }^{5}$. Este catálogo de riscos possibilita a realização da gestão de riscos sem depender de um especialista na área, uma vez que já foram mapeadas diversas possibilidades de controle e tratamento. Entretanto, verifica-se a necessidade de aplicar a metodologia GRATIC em outros processos de aquisição de TIC para o mapeamento de outros riscos, visando a melhoria contínua da solução proposta neste estudo.

\section{Referências}

Brasil. Ministério da Economia. Secretaria de Governo Digital. (2019). "Instrução Normativa SGD/ME No 1, de 4 de abril de 2019”, Brasília-DF.

Controladoria Geral da União. (2018c). "Metodologia de Gestão de Riscos", Brasília, DF.

Ministério do Planejamento e Controladoria Geral da União. (2016) "Instrução Normativa Conjunta No 1/2016, de 10 de maio de 2016", Brasília-DF.

. Ministério do Planejamento, Orçamento e Gestão. (2017). "Instrução Normativa MPOG No 5, de 26 de maio de 2017”, Brasília-DF.

.Tribunal de Contas União. (2018). "Relatório Técnico completo de acompanhamento governança pública (2018)", Brasília-DF.

5 Repositório Digital de Informações 

DF.

Tribunal de Contas União. (2014). "Riscos e controles nas aquisições”, Brasília-

Tribunal de Contas União. (2018b). "Sumários executivos: acompanhamento de governança pública organizacional 2018”, Brasília-DF.

Bermejo, Paulo Henrique de Souza et al. (2019). "ForRisco: Gerenciamento de Riscos em Instituições Públicas", $2^{\mathrm{a}}$ ed. Brasília-DF: Ed. Evobiz.

Gil, Antônio Carlos. (2019). "Métodos e Técnicas de Pesquisa Social”, $7^{\mathrm{a}}$ ed. São Paulo: Atlas.

HM GOVERNMENT. (2019). "The Orange Book: Management of Risk (Principles e Concepts)".

Hopkin, Paul. (2018). "Fundamentals of Risk Management: Understanding, Evaluating and Implementing Effective Risk Management", 5a ed. IRM. KoganPage.

International Organization for Standardization. (2018). "Risk Management (Guidelines, provides principles, framework an a process for managing Risk)".

Maarconi, Marina de Andrade e Lakatos, Eva Maria. (2017). "Metodologia de Trabalho Científico", $8^{a}$ ed. Editora: Atlas.

Nobre, Leonardo Santana. (2017). "Proposta de metodologia de gestão de riscos para as contratações de TI da Funasa", Dissertação de Mestrado Profissional em Computação Aplicada. UNB. Brasília-DF.

Parreira, Glauco Cintra. (2018). "Modelo de decisão para gestão de riscos de contratos de serviços de TI no Poder Judiciário Brasileiro", Dissertação de Mestrado UNB. Brasília-DF.

Peffers, Ken et al. (2007). "A Design Science Research Methodology for Information Systems Research", Journal of Management Information Systems, v. 24, n. 3, p.45-77.

Pires, Tatieures G., Cavalcante, Sueli M. de, Correa, Denise M. M. C. e Neto, Denise M. M. C. (2016). "Gestão de Riscos nas Aquisições de Soluções de TI: Uma Análise Crítica dos Modelos de Boas Práticas", Anais do EATI - Encontro Anual de Tecnologia da Informação e STIN - Simpósio de Tecnologia da Informação da Região Noroeste do RS.

Silva, Dyego Alves da., Oliveira, Edgard Costa de. e Canedo, Edna Dias. (2016). "Avaliação de Riscos do Processo de Planejamento da Contratação de TI: Uma Proposta para Órgãos Governamentais Brasileiros", Revista Brasileira de Sistemas de Informação. Rio de Janeiro, vol. 9 Nº 1, pp. 168-186.

Silva, Hildiene Castro. (2014). "Gestão de Riscos em aquisições de TI: proposta de avaliação de maturidade do processo de contratação de TI da IN04/SLTI no âmbito do INSS", Dissertação de Mestrado, UNB, Brasília, DF.

Souza, Kleberson e Brasil, Franklin. (2017). "Como Gerenciar Riscos na Administração Pública: Estudo Prático em Licitações”, Curitiba, PR: Editora Negócios Públicos do Brasil.

YIN, Robert K. (2015). "Estudo de caso: planejamento e métodos”, 5ª ed. Porto Alegre, RS: Bookman. 